\title{
REPRESENTING OTHERS CARL THOMPSON DALAM NOVEL TRAVELER'S TALE: BELOK KANAN BARCELONA
}

\author{
Galang Prastowo dan Ikha Adhi Wijaya \\ Universitas Negeri Yogyakarta \\ galang.prastowo@uny.ac.id
}

\begin{abstract}
(Title: Representing Others Carl Thompson in The Novel "Traveler's Tale: Belok Kanan Barcelona"). This research appllied representing other Carl Thomson approach in a novel entitled Traveler's Tale: Belok Kanan Barcelona. Representing other in the mentioned novel was conducted to expound on how the writer portrays west and east culture as the travel writing. The writer applied Carl Thompson's Theory to indentifying Travelers Tale novel; Belok Kanan Barcelona from the representing other's concept trough descriptive and qualitative approach. The research result has shown that they appraise the west culture than the east culture - tend to belittle the east culture. The revealing of the two differnt culture features is represented in a form of idiology in travel writing. Ergo, from this research, we can conclude that the writing technique tends to exergerating the west (self), the comparison result tends to belittle the east culture (others).
\end{abstract}

Keywords: travel writing, representing other, carl thompson.

\section{PENDAHULUAN}

Perkembangan transportasi udara dan banyaknya biro perjalanan sangat mempengaruhi perkembangan pariwisata di dalam maupun luar negeri. Beraneka kemudahan yang ditawarkan oleh biro perjalanan dan dukungan harga murah maskapai penerbangan membuat banyak orang ingin melakukan perjalanan domestik maupun internasional, untuk wisata ataupun menempuh pendidikan. Ketika melakukan perjalanan, manusia sering menemukan hal-hal yang baru. Tentunya mereka menghadapi banyak perbedaan dan persamaan yang merupakan sebuah konfrontasi ataupun negosiasi kompleks, hingga dapat dikatakan bahwa perjalanan merupakan sebuah negosiasi antara diri (self) dan yang lain (other).
Seiring berkembangnya sosial media sekarang ini, orang-orang yang melakukan perjalanan, selain mengabadikan gambar mereka untuk diunggah di media sosial pribadinya, mereka juga berhasrat menuliskan kisah perjalanannya dan menggambarkan keadaan yang dialaminya. Tentu tidak semua pergerakannya dituliskan dalam sebuah catatan, namun hanya peristiwa yang menarik dan berkesan saja yang ditulisnya dalam sebuah catatan perjalanan. Kisah-kisah perjalanan inilah yang kemudian dijadikan sebuah buku catatan perjalanan yang dikenal dengan travel writing. Buku atau novel jenis ini sekarang sudah banyak berkembang dan menjamur di kalangan anak muda masa kini yang dianggap sebagai sesuatu yang keren. Seperti novel Traveler's Tale: Belok Kanan 
Barcelona (2007) karya Aditya Mulya dkk., 99 Cahaya di Langit Eropa (2011), Bulan Terbelah di Langit Amerika (2014) karya Hanum Salsabila Rais dan Rangga Almahendra, Edensor (2007) karya Andrea Hirata, Off The Record (2018) karya Ria S.W., dll.

Travel writing merupakan genre penulisan yang berfokus pada tempat, baik imajiner maupun kenyataan. Genre ini mencakup beberapa hal, dari tulisan dokumenter hingga yang menggugah, dari studi literatur hingga jurnalistik, dari yang penuh humor hingga tulisan serius (George, 2004). Genre ini berhubungan erat dengan tourisme, juga dengan karya-karya seperti ulasan dan buku panduan, yang bertujuan mengedukasi pembaca tentang destinasi, memberikan beberapa tips tentang tempat-tempat tujuan, dan menginspirasi orang untuk mengunjunginya. Tulisan yang baik akan memberi gambaran jelas kepada pembaca tentang suatu tempat dengan cara yang bermanfaat dan menghibur. Genre ini penulisannya paling ramah, siap mengakomodasi semua hal.

Travel writing yaitu adanya pertemuan antara self dan other yang terjadi akibat adanya pergerakan melintasi ruang-ruang dan kemudian direkam atas pertemuan-pertemuan itu dan negoisasi-negoisasi perbedaan dan persamaan yang terjadi dan melingkupi antara self dan others (Thompson, 2011: 63). Travel writing dibuat melalui sebuah pengalaman sang pengarang yang memposisikan dirinya sebagai seorang reporter yang merekam perjalanan-perjalanannya, pengarang mengkonkritkan pengalaman tersebut dalam sebuah teks (Faruk, 2007). Travel writing dapat dianggap sebagai buku perjalanan modern, genre ini bisa dilihat dengan perspektif yang lebih luas, dimana etnografi modern juga bisa dianggap sebagai bentuk sederhana dari travel writing. Hal serupa juga terjadi pada teks-teks lain yang menceritakan tentang pengalaman lapangan dan perjalanan. Secara esensial, catatan perjalan merupakan fiksi dari representasi yang faktual (Thompson, 2011: 63).

Travelers' Tale merupakan karya keroyokan dari empat penulis yang punya hobi traveling. Berawal dari sharing pengalaman traveling, empat orang yang terdiri dari Adhitya Mulya, Ninit Yunita, Alaya, dan Iman Hidajat membagi pengalaman traveling mereka dalam kemasan cerita. Novel ringan bertajuk Traveler's Tale: Belok Kanan Barcelona menceritakan perjalanan empat orang sahabat, yaitu Francis, Jusuf (Ucup), Retno, dan Farah yang melakukan perjalanan keliling dunia secara terpisah dengan satu tujuan akhir yang sama, Barcelona. Di sana mereka berjanji bertemu untuk menghadiri pernikahan Francis. Berbagai tempat di dunia terlibat dalam perjalanan mereka.

Deskripsi detail perjalanan yang tertuang dalam novel ini membawa kita hanyut dalam dunia traveling. Bumbu persahabatan yang ditaburi kisah cinta diantara keempat petualang ini membuat kita tak menyadari bahwa sebenarnya angan kita secara tidak langsung telah dibawa keliling dunia. Gaya penceritaan dalam empat sudut pandang masing-masing tokoh yang berbeda pembawaannya membawa kesegaran tersendiri, dan yang menambah seru lagi adalah sisipan tips untuk traveler yang diselipkan di beberapa bagian cerita. Menarik menyimak cara bercerita keempat tokoh ini. Farah menggunakan kata ganti gue, Jusuf dengan gua, Retno dengan saya, dan Francis dengan $a k u$, hal tersebut dikarenakan penulis memakai sudut pandang orang pertama semua.

Dalam novel Aditya Mulya tersebut, pengarang banyak menceritakan keindahan 
dan mengagungkan barat atau Eropa dan lebih memandang keterbelakangan atau merendahkan Timur, yang dalam novel ini tergambar dari tokoh Jusuf yang tinggal di Cape Town, Afrika Selatan, dan banyak mengalai perang saudara di beberapa negara Afrika. Sedangkan keindahan-keindahan Eropa yang tentram tergambar dari perjalanan Retno dan Farah pada beberapa negara Eropa yang mereka singgahi.

Penelitian ini memaparkan bagaimana penggambaran barat dan timur pada novel Traveler's Tale: Belok Kanan Barcelona. Selain itu, gaya penulisan pengarang dalam novel ini lebih memprioritasikan fakta-fakta tentang penemuan wilayah baru dan juga menyertakan reaksi-reaksi serta refleksi diri terhadap lokasi-lokasi baru yang mereka temui. Pengarang juga memberi gambaran terhadap suatu kebudayaan dengan derajat yang berbeda, hal tersebut juga akan coba dipaparkan dalam penelitian ini agar paradigma pengarang yaitu Aditya Mulya mengenai barat dan timur dapat diketahui..

Dari beberapa latar belakan tersebut, maka ada beberapa hal yang harus dijelaskan pada persoalan travel writing. Travel writing adalah satu genre dalam penulisan yang berfokus pada tempat, baik imajiner maupun real. Genre ini mencakup banyak hal, dari tulisan dokumenter hingga yang menggugah, dari studi literatur hingga jurnalistik, dari yang penuh humor hingga tulisan serius (George, 2004). Carl Thompson mengungkapkan secara detil hal-hal yang menjadi prinsip dasar sebuah travel writing.

Pertama, Reporting The World, merupakan suatu hal bahwa travel writing harus melaporkan keadaan dunia yang luas, manusia dan tempat-tempat yang tidak biasa. Travel Writing's principal bussines has been to bring news of the wider world, and to disseminate information about unfamiliar people and places (Thompson, 2011: 62).

Kedua, Revealing Self, yaitu sebuah pernyataan sebagai bentuk nilai-nilai asumsi diri penulis travel writing terhadap apa yang dialami selama perjalanan. Carl Thompson menjelaskan bahwa dalam perkembangan travel writing, revealing self mulai dirasakan pada akhir abad ke-18. Ditandai oleh gaya penulisan subjektifitas dan realisasi diri sebagai karakter perubahan gaya penulisan dari era Enlightment ke era Romantisism (Thompson, 2011: 62). Enlightenment lebih memprioritasikan fakta-fakta tentang penemuan wilayah baru, sedangkan Romanticism tidak hanya menyurvei lokasi-lokasi baru, namun juga menyertakan reaksi-reaksi serta refleksi diri terhadap lokasi-lokasi baru yang mereka temui. Tetapi banyak travel writing dari akhir abad 18 hingga sekarang menerapkan ciri Enlightenment dan Romanticism. Sehingga wacananya tidak hanya bersifat scientificl intelektual, tetapi juga literary/autobiography (Thompson, 2011: 119).

Ketiga, Representing Others, merupakan sebuah upaya dalam mengungkapkan budaya penulis dan budaya daerah yang dikunjungi yang dikisahkan dalam catatan perjalanan. Thompson menyatakan bahwa dalam mengungkapkan sebuah kebudayaan, para traveler umumnya membuat dikotomi dalam lingkup perbedaan antara kebudayaan dirinya (self) dan kebudayaan yang dikujungi (other). This is a much-used term in recent travel writing studies, although confusingly it is often used in two slightly different senses. In a weaker, more general sense, 'othering' simply denotes the process by which the members of one culture identify and highlight the differences between themselves and the members of another culture (Thompson, 2011: 132).

Dalam dikotomi tersebut adanya motifmotif wacana othering dari para travel writer 
yang mana dari pernyataan tersebut melegitimasi gambaran mereka terhadap suatu kebudayaan dengan derajat yang berbeda. In a stronger sense, however, it has come to refer more specifically to the processes and strategies by which one culture depicts another culture as not only different but also inferior to itself (Thompson, 2011: 132). Hal tersebut juga menjadi landasan mengapa orang-orang barat yang berhak mengelola tanah dan isinya dikarenakan perbedaan derajat tingkat kebudayaan dimana orang barat self dikatakan manusia sedangkan the other setengah manusia dan bumi hanya berhak dikelola oleh manusia.

Pengungkapan dua unsur budaya yang berbeda dalam travel writing dengan derajat yang berbeda diungkapkan oleh Thompson sebagai bentuk ideology dalam travel writing. Sebagai suatu kencenderungan dalam teknik penulisan yang meninggikan kebudayaan Barat (self) dan merendahkan kebudayaan Timur atau others sehingga menciptakan ruang bermusuhan (Thompson, 2011: 134). Isu ini lebih lanjut didalami pada orientalisme, sebuah kajian paskakolonialisme dan travel writing oleh Said. Adanya orientalisme, membuat para kritikus dan sejarawan melakukan investigasi terhadap konvensi retorika dan ideologi dasar dari laporanlaporan barat terhadap daerah lain (Said: 2010). Munculnya pertentangan terhadap wacana-wacana yang muncul dari laporanlaporan Barat terhadap Timur.

\section{METODE}

Penelitian ini menggunakan pendekatan deskriptif kualitatif. Suatu pendekatan yang mengandaikan data dalam penelitian berupa kata, kalimat, dan paragraf yang sesuai dengan objek penelitian (Miles dan Huberman, 2009: 15). Sumber data penelitian ini adalah novel karya Aditya Mulya dkk. yang berjudul Traveler's Tale: Belok Kanan Barcelona, diterbitkan oleh Gagas Media pada tahun 2007.

Penelitian ini menggunakan teori travel writing Carl Thompson. Prinsip teori travel writing Carl Thompson ada tiga (3), yaitu reporting the world, revealing self, dan representing other. Penelitian ini menggunakan prinsip yang ketiga, yaitu represting other, digunakan untuk mengungkapkan budaya penulis dan budaya daerah yang dikunjungi yang dikisahkan dalam catatan perjalanan, juga melihat reaksi-reaksi serta refleksi diri (traveler) terhadap lokasi-lokasi baru yang mereka temui.

Analisis data dilakukan melalui kegiatan kategorisasi dan inferensi. Kategorisasi digunakan untuk mengelompokkan data sesuai prinsip teori travel writing dengan prinsip represting other. Inferensi dilakukan untuk mengintepretasikan, memahami, dan menyimpulkan hasil penelitian sesuai dengan permasalahan penelitian.

\section{PEMBAHASAN}

Traveler's Tale: Belok Kanan Barcelona ini bercerita tentang 4 sahabat yang telah berteman sejak lama yang terpisah di benua karena hal pekerjaan. Keempat sahabat itu adalah Francis yang berprofesi sebagai pianis, Retno yang bekerja di kedutaan Indonesia untuk Coppenhagen, Farah yang bekerja di Vietnam dan Jusuf yang bekerja di Afrika Selatan. Cerita bermula ketika Francis mengirimkan e-mail kepada 3 sahabatnya yang berisi kabar bahwa ia akan menikah bersama dengan seorang gadis Catalan di Barcelona. Membaca berita itu, Farah yang sejak lama memendam perasaan kepada Francis merasa harus pergi untuk mencegah pernikahan tersebut. Retno akan pergi dengan 
tujuan untuk bertemu dengan ketiga sahabatnya. Jusuf pergi dengan tujuan untuk mencegah Farah menyatakan cinta kepada Francis. Meski harus menguras uang tabungan mereka, mereka tetap pergi ke Barcelona. Pada perjalanan tersebut, terjadi banyak peristiwa, mulai dari Farah yang harus naik pesawat padahal ia takut, bertemu gypsi, sampai pada Jusuf yang harus tejebak di wilayah konflik. Sampai akhirnya mereka bertemu di Barcelona, tetapi Francis membatalkan pernikahannya karena ia mencintai Retno. Farah yang cintanya ditolak oleh Francis pulang ke Vietnam dengan penuh rasa kecewa. Ketika di bandara di Barcelona, Farah dilamar oleh Jusuf dan akhirnya mereka menikah.

Ditulis oleh 4 penulis, setiap bab menceritakan setiap tokoh dan semuanya menggunakan sudut pandang orang pertama. Tidak perlu bingung, karena sebagian besar bahasa yang digunakan adalah bahasa gaul yang memang sudah akrab di telinga kita sehari-hari. Oleh karena itu, pembawaan setiap penulis yang sepertinya mewakili setiap tokoh dan karakter dalam buku bisa terlihat dan cukup bisa dibedakan. Empat sahabat, terdiri dari dua laki-laki dan dua perempuan. Masing-masing tokoh dalam novel memiliki keunikan yang berbeda-beda. Setiap tokoh tidak terlalu dieksplor secara mendalam karakternya, namun tidak juga terlalu dangkal. Novel ini banyak menonjolkan lebih banyak tentang perbedaan ras diantara keempatnya, yang secara unik bisa membuat mereka semua bersahabat.

Novel ini kurang lebih adalah travelogue yang dibalut dalam bentuk fiksi. Membagi menjadi 4 tokoh yang datang dari berbagai arah benua menuju Barcelona mewakilkan banyaknya tempat yang diceritakan dalam novel. Tidak hanya membahas tentang lokasi wisata, namun ada juga yang membahas keunikan-keunikan lainnya seperti nama bandara yang sulit disebutkan. Hal yang menarik lagi adalah, penulis juga memberikan catatan yang cukup berguna sebagai bekal bepergian. Kehadiran catatan kaki dalam novel ini jangan dikira sebagai suatu hal yang serius, memang ada yang berupa fakta, namun ada juga yang isinya berupa banyolan dari si tokoh. Hal seperti inilah yang membuat pembaca lebih tertarik dan terhibur.

Penulisan novel Traveler's Tale: Belok Kanan Barcelona, pengarang menggunakan footnote, yaitu media penulis untuk menyertakan informasi akan suatu hal yang sekiranya kurang dimengerti pembaca. Namun, di tangan Adhitya Mulya dkk menjadi lain. Mereka menggunakan footnote selain untuk memberikan informasi tambahan, tetapi juga digunakan untuk media komedi yang efektif. Hal ini terdapat dalam potongan cerita ini.

"Adalah shocking bagi gua bahwa Farah nekat pergi, apalagi untuk menghentikan pernikahan Francis. Manusia yang satu itu memang emosional tapi itu juga yang membuat gua jatuh cinta sama dia $^{7}$. Orang yang passionate dan tidak dapat ditebak.

. .

$\overline{7 \quad \text { Farah, }}$ bukan Francis. (Mulya, 2007: 80)

Sebenarnya, ini adalah kelancangan dan kekeliruan dalam menggunakan fungsi footnote. Namun, dengan cerdik penulis menjadikannya sebagai media komedi yang benar-benar efektif. Bukan hanya lucu, tetapi juga membuat para pembaca bergumam dalam hati. 
Dalam Traveler's Tale: Belok Kanan Barcelona, pengarang banyak menceritakan keindahan dan mengagungkan barat atau Eropa dan lebih memandang keterbelakangan atau merendahkan Timur, yang dalam novel ini tergambar dari tokoh Jusuf yang tinggal di Cape Town, Afrika Selatan, dan banyak mengalai perang saudara di beberapa negara Afrika. Keindahan-keindahan Eropa yang tenteram tergambar dari perjalanan Retno dan Farah pada beberapa negara Eropa yang mereka singgahi.

"Sayangnya bos gua membawahi area barat Afrika, yang mana kebanyakan negara sedang

1. perang dengan satu sama lain atau,

2. perang saudara atau,

3. sedang terkena embargo dari PBB atau,

4. paket combo ketiganya."

(Mulya, 2007: 18)

Kutipan di atas adalah cerita dari Jusuf (Ucup) yang menggambarkan ketidakberuntungannya yang ditugaskan di bagian barat Afrika yang merupakan daerah penuh konflik. Hal tersebut tentunya penggambaran pengarang tentang Afrika yang dia ketahui, yaitu wilayah yang banyak mengalami konflik perang saudara atau embargo dari PBB. Selain itu juga ada kutipan betapa buruknya penerbangan saat di Kenya seperti berikut.

"Flight BE-201 to Abidjan, Cote d'Ivoire is now ready to board. ALL passenger may proceed."

"Nah yang gini-gini nih yang gak ngenakin. Di kebanyakan airlines, kita diberi assigned seat dan dipanggil per berapa baris. Di beberapa airlines di Afrika, seperti Benin Gulf Air ini, kita dikasih free seating AJAH. Yang ada setiap kali boarding, gua mesti rugby tackle manusia-manusia segede bajaj."

(Mulya, 2007: 80)

Cerita Ucup tersebut saat berada di bandara Kenya hendak pulang ke Afrika Selatan. Pengarang menggambarkan betapa tidak nyamannya layanan dan sistem penerbangan di beberapa negara Afrika seperti Kenya yang mengharuskan para penumpang berebut tempat duduk seperti keinginannya sendiri. Pengarang lebih memperburuk gambaran penerbangan tersebut dengan terjadinya emergency landing yang dialami Ucup seperti kutipan berikut.

"HELLO! This is flight KE-563 calling Airport Felix Phou ... Phou ... Phououo ...."

"Nama belum selesai pesawat udah nyungsep duluan semua airp. . . . ARRGGHHH!

Ada dua hal yang menantang bagi gua. Pertama adalah cari gara-gara dengan pegulat sumo. Kedua adalah naik Benin Gulf Air. Bukan karena kenyataannya bahwa airline ini masih pake balingbaling."

(Mulya, 2007: 83)

Emergency landing ini digambarkan pengarang yang dialami Ucup saat penerbangan dari Kenya bertujuan ke Afrika Selatan. Sering terjadinya emergency landing di sana digambarkan betapa heroiknya sang pilot yang merasa dirinya James Bond yang bisa mendaratkan pesawat baling-baling yang akhirnya terjadi emergency landing. Pengarang juga menggambarkan situasi di Pantai Gading yang tiba-tiba mengalami perang. 
"Semalam di berita pukul sembilan, para pemberontak menyatakan bahwa perang dibuka kembali. Kita resmi dalam situasi perang." (Mulya, 2007: 88)

....

"Setidaknya dua tahun terakhir ada gencatan senjata jangka panjang."

....

"Pada pukul 14.36, pemimpin pemberontak melalui saluran TV nasional - yang mereka bajak - mengumumkan deklarasi perang. Ow, crap. Bersamaan dengan itu banyak negara mendaratkan pesawat mereka untuk mengevakuasi warga negara mereka dari Cote d'Ivoire." (Mulya, 2007: 89)

....

"Suara helikopter dan rentetan senjata terus mendengung di udara sore Abidjan. Dari Rue de Canebiere, gua bisa melihat merahnya matahari terbenam menghitamkan kota menjadi siluet dan mengeraskan garis-garis asap perang ." (Mulya, 2007: 90)

Pengarang menggambarkan situasi perang yang terjadi di Pantai Gading dengan sangat ironisnya, seperti stasiun TV nasional yang dibajak, penjarahan toko-toko, suara baku tembak dan asap di mana-mana. Banyak gedung-gedung terbakar dan mobil-mobil yang hancur. Bahkan beberapa angkatan bersenjata pemerintah Pantai Gading banyak yang menjadi tentara bayaran untuk disewa para orang kaya untuk mengamankan dirinya dan keluarganya. Pengarang sangat fasih dalam menggambarkan keterbelakangan di negara Afrika atau merendahkan Timur. Berbeda dengan gambaran yang ada di eropa, yang dianggap lebih baik dari pad Timur/Afrika. Hal tersebut diperlihatkan saat Ucup berada di Spanyol, dia dianggap teroris dan akhirnya ditangkap polisi Spanyol.
"Gua sedang mengantre dengan canggung di passport control Puerte de Algeciras ketika empat orang polisi Spanyol mulai ceeping up dari belakang. Sang passport controler memberikan anggukan yang gua terjemahkan sebagai bentuk pemberian ijin untuk melangkah ketika tiba-tiba gua dibekuk." (Mulya, 2007: 191)

....

"Maafkan kami, Senor. Kami kira anda termasuk jaringan Al-Qaeda di Asia Timur. Pas sekali. Paspor anda Indonesia. Visa aktif semua ke negara-negara Afrika yang berkonflik, Anda berwajah Asia dan on top of everything else Anda bernama Jusuf." (Mulya, 2007: 194)

Kutipan tersebut menggambarkan pandangan pengarang melalui orang barat (Spanyol), yang memandang orang yang bernama Jusuf dan berasal dari negara Asia atau Afrika kenyakan adalah teroris. Jusuf diperlakukan tidak adil dan tidak semestinya, dia ditangkap dan di setrum menggunakan stun gun tanpa diperiksa atau diidentifikasi terlebih dahulu. Orang barat hanya melihat cover orang timur saja tanpa memandang berderajat sama, mereka cenderung lebih berfikiran negatif terhadap orang timur.

Penggambaran pengarang yang merendahkan timut tidak hanya terjadi pada penceritaan Jusuf, tetapi juga terjadi pada Farah. Melalui Farah yang bekerja dan tinggal di Vietnam, pengarang menceritakan pengalaman terhadap transportasi darat di Vietnam yang kurang nyaman seperti pada kutipan berikut.

"Deru mesin yang tidak terawat mengalahkan suara reyotnya besi-besi tua di dalam bus tua yang gue tumpangi." (Mulya, 2007: 5) 
Kutipan penggambaran kondisi transportasi di Vietnam yang digambarkan Farah yang merendahkan timur, padahal Vietnam merupakan negara dengan perkembangan ekonomi kedua terpesat di dunia, pada tahun 2007. Farah juga menggambarkan betapa keringnya Yordania seperti pada kutipan berikut.

"Bukan karena tempat ini ga indah, tetapi di sini kering sekali. Sebagian dari Yordania adalah padang pasir. ... Bahkan bangunan-bangunan di sini pun warnanya mirip, putih krem kecokelatan berbentuk kotak-kotak."

(Mulya, 2007: 71)

Yordania diceritakan pengarang melalui Farah yang singgak ke Yordania sebelum pergi ke Barcelona. Dia melihat betapa keringnya Yordania, dengan bangunan-bangunan yang tidak menarik, berwarna mirip, putih krem kecoklatan seperti warna pasir gurun.

Kontras dengan penggambaran pengarang terhadap timur (Asia dan Afrika), pengarang memperlihatkan betapa indahnya barat (Eropa) dengan tempat-tempat yang indah dan nyaman untuk dikunjungi. Pengarang menampilkan gambar-gambar indah dan tempattempat yang menawan di Eropa. Pengarang yang lebih meninggikan kebudayaan barat disampaikan melalui tokoh Retno dan Farah yang pada perjalanan menuju Barcelona, mereka sempatkan singgah dulu di beberapa negara Eropa seperti berikut.

"Sabtu pukul 10 pagi seperti ini, bukan hanya saya yang sudah menggenggam cangkir cappuccino. Sebagian pengunjung lain ada yang membaca koran, tekun membaca majalah, ... . Ada pejalan kaki yang seru menenteng tas belanja dari $\mathrm{H}$ \&
M. Ada juga yang bersepeda santai menuju suatu tempat. Seorang laki-laki bertubuh tambun, berjalan kaki ditemani anjingnya yang setia. Ya, ini Kopenhagen. Pemandangan tadi, biasa terlihat di manamana." (Mulya, 2007: 32)

Melalui Retno, pengarang menggambarkan betapa nyaman dan tentramnya kehidupan di Kopenhagen, Denmark. Orang yang di pagi hari minum kopi di cafe dan melihat orang berlalu lalang menikmati aktifitas masingmasing yang santai. Berbeda dengan penggambaran yang terjadi pada Ucup yang berada di Afrika dengan berbagai masalahnya. Bahkan ada kutipan dari cerita Retno yang sangat rasis terhadap wanita Afrika dengan dibandingkan seperti berikut.

"Mulai dari perempuan-perempuan Eropa Timur yang luat biasa cantik sampai perempuan-perempuan berkulit gelap keturunan Afrika, ada di sana." (Mulya, 2007: 107)

Kutipan tersebut jelas merendahkan timur dan menjunjung tinggi barat. Pengarang sangat kental dalam gaya penulisannya yang lebih melihat barat tinggi dan timur rendah. Rasisme seperti itu juga terjadi ketika dikatakan ada orang kulit hitam yang menawarkan ganja pada orang-orang yang lalu lalang. Hal tersebut kontras dengan adanya gereja indah disekitarnya yang digambarkan pengarang.

"Di sana terlihat gereja tua yang indah. Pemandangannya persis seperti Venesia di Italia. Gedung yang terlihat mengambang di atas air. Sinar lampu temaram seolah menjadi ganda karena bayangan yang terlihat di kanal.” (Mulya, 2007: 108) 
Latar belakang pengarang yang mungkin beragama Nasrani juga terlihat dengan caranya menggambarkan keindahan gereja yang ada di Amsterdam tersebut. Pengarang juga menceritakan sejarah agama Kristen di Hongaria.

Rupa menawan orang-orang barat juga digambarkan oleh pengarang. Seperti dalam cerita Retno yang telah sampai di kota mode, Milan, Italia.

"Sambil menunggu metro, saya memerhatikan orang-orang Italia. Mereka ratarata berwajah cantik, ganteng, dan modis. Tidak heran bila Milan menjadi salah satu kota penting di dunia fashion." (Mulya, 2007: 152)

Kutipan yang mewakili kekaguman pengarang terhadap kota mode Milan di Italia tersebut disampaikan oleh tokoh Retno. Selain Milan, Retno juga menggambarkan keindahan Venesia saat dia menaiki vaporetti, yaitu bus air yang beroprasi selain gondola. Setelah sesampainya Retno di Seville, kesan pertama tentang Seville pun ditunjukkan.

"Kesan pertama yang saya dapati ketika merasakan udara adalah Seville kota yang bersih.” (Mulya, 2007: 158) ....

"Penduduknya sangat sadar dengan para traveler dan turis yang datang berkunjung. Bangunannya cantik-cantik. . . . Seville adalah kota di bagian Andalusia - Spanyol yang sangat terkenal. Kaya dengan sejarah.” (Mulya, 2007: 159)

Kesan pertama Retno sampai di Seville sangat antusias dengan keadaan yang ada. Dengan udara yang bersih dan tidak ada pengemis-pengemis yang tidur di teras toko, dia memuji bangunan-bangunan yang cantik. Banyak bangunan yang dulunya masjid sudah menjadi katedral yang mempunyai ukiran kaligrafi yang sangat indah. Masih banyak keindahan-keidahan yang diperlihatkan pengarang pada perjalanan Retno dan Farah, seperti keindahan Barcelona yang diungkapkan Retno. Sedangkan Farah banyak mengungkapkan keindahan di Wina saat dia bertemu traveler lain yang mengajaknya mampir ke Wina. Dia memaparkan Mozart di Wina, wiener schitzel, apfelstrudel, kebun anggur Grinzing, dan pemandangan alam saat menuju Spanyol menggunakan mobil. Tidak hanya keindahan Eropa yang digambarkan pengarang melalui tokoh, tetapi juga Amerika, yaitu pada tokoh Francis yang menggambarkan keindahan toko buku.

"Aku berlari memasuki Barnes \& Noble, toko buku besar di tengah-tengan Country Club Plaza. Oh ya, Country Club Plaza adalah daerah pertokoan terbuka di kota ini. Saking sang arsitek begitu cintanya sama Kota Seville di Spanyol, ia membangun kembaran menara Giralda sama, seperti yang ada di Kota Seville." (Mulya, 2007: 50)

Penggambaran toko buku tersebut dilengkapi dengan foto yang terdapat di samping cerita. Toko yang berada di Kansas City, Amerika ini disinggahi Francis karena ia berteduh dari hujan deras yang turun. Kemudian Francis menuju lantai dua toko tersebut dan memesan secangkir English Breakfast dan duduk di sisi jendela yang menghadap ke Giralda Tower. 


\section{KESIMPULAN}

Buku Traveler's Tale: Belok Kanan Barcelona kurang lebih adalah travelogue yang dibalut dalam bentuk fiksi. Membagi menjadi 4 tokoh yang datang dari berbagai arah benua menuju Barcelona mewakilkan banyaknya tempat yang diceritakan dalam buku. Tidak hanya membahas tentang lokasi wisata, namun ada juga yang membahas keunikan seperti nama bandara yang sulit disebutkan. Penulis juga memberikan catatan yang cukup berguna sebagai bekal bepergian. Footnote dalam novel berupa media penulis untuk menyertakan informasi akan suatu hal yang sekiranya kurang dimengerti pembaca, pengarang menggunakan footnote untuk memberikan informasi tambahan, tetapi juga digunakan untuk media komedi yang efektif.

Dalam novel Traveler's Tale: Belok Kanan Barcelona, pengarang banyak menceritakan keindahan dan mengagungkan barat atau Eropa dan lebih memandang keterbelakangan atau merendahkan Timur, yang dalam novel ini tergambar dari tokoh Jusuf yang tinggal di Cape Town, Afrika Selatan, dan banyak mengalai perang saudara di beberapa negara Afrika. Sedangkan keindahan-keindahan Eropa yang tentram tergambar dari perjalanan Retno dan Farah pada beberapa negara Eropa yang mereka singgahi. Pengungkapan dua unsur budaya yang berbeda dengan derajat yang berbeda diungkapkan dalam novel Aditya Mulya dkk sebagai bentuk ideology dalam travel writing. Sebagai suatu kencenderungan dalam teknik penulisan yang meninggikan kebudayaan Barat (self) dan merendahkan kebudayaan Timur atau others.

\section{DAFTAR PUSTAKA}

Faruk. (2007). Belenggu Pasca-Kolonial. Yogyakarta: Pustaka Pelajar.

George, D. (2007). Travel Writing: Expert Advice from The World's Leading Travel Publisher. Melbourne: Lonely Planet's.

Miles, M. B. dan Huberman, A. M. (2009). Analisis Data Kualitatif: Buku Sumber Tentang Metode-metode Baru. Jakarta: UIP.

Mulya, A. dkk. (2007). Traveler's Tale: Belok Kanan Barcelona. Jakarta Selatan: Gagas Media.

Said, E. W. (2010). Orientalisme. Yogyakarta: Pustaka Pelajar.

Thompson, C. (2011). Travel Writing: The New Critical Idiom. New York: Routledge 